\title{
WEATHER EXTREMES AND AGRICULTURE
}

\author{
Kamaljit Ray ${ }^{1, *}$, Kopal Arora ${ }^{1}$ and A.K.Srivastav ${ }^{2}$ \\ ${ }^{1}$ Ministry of Earth Sciences, New Delhi, India, Email*:kamal.ray@nic.in, kopal.arora@gov.in \\ ${ }^{2}$ India Meteorological Department, CRS, Pune, India, email: aks_ncc2004@yahoo.co.in
}

\section{Commission III, WG III/10}

KEY WORDS: Heat Waves, Lightning, Calamities, Disaster, Agriculture

\begin{abstract}
:
Agricultural production is highly vulnerable to weather extremes. The changing patterns of these extreme events have significant implications on food security. Unprecedented weather extremes can strongly impact crop yield regionally and globally. The present study examines change in the frequency of extreme events (Floods, heat/cold waves, Tropical Cyclones and Lightning) over half a century from 1960 to 2016 and its effects on crop yield over India. The analysis aims at identifying the regions which are more susceptible to extreme events and the changing patterns in the occurrence of these events. Case studies to analyse the influence of the extremes on yields are also attempted for some of the regions with a high frequency of these events.
\end{abstract}

\section{INTRODUCTION}

Extreme weather events like Heat Waves, Cold waves, Cyclones, Floods, Lightning etc have affected various regions of Indian subcontinent but the intensity and frequency appears to have increased in recent years. The Floods in Uttarakhand during 14-18 June, 2013 was one of the most devastating natural disasters that led to massive landslides and avalanches at multiple places and claimed more than 5,000 human lives, apart from damage to public/private property and cash crops especially apple crops. During the second week of September, 2014, floods in Jammu \& Kashmir claimed over 200 lives and left more than 4 lakh people stranded for many days besides causing widespread damage to the agriculture and public/private property. In 2015 again during the North East (NE) Monsoons, floods and heavy rains claimed 322 human lives apart from heavy damage to agriculture in Tamil Nadu (particularly Chennai). This year Kerala received $2346.3 \mathrm{~mm}$ of rainfall instead of average $1649.55 \mathrm{~mm}$ during Monsoon period. The month of August received unusually high rainfall, which led to state-wide floods. More than 53000 people were moved to relief camps, 217 people died and around 56,844 ha of cropped area was affected by floods. Paddy \& banana were worst hit in Kerala floods. In 2015 heavy rains accompanied with hailstorm damaged wheat and other Rabi crops in Punjab and Haryana. In 2013 during the hailstorm events in February agriculture crops in 1,47986 hectares and horticulture crops in $1,45,000$ hectares were damaged in Andhra Pradesh due to hailstorms (Chattopadhyay et.al.,2017).

India Meteorological Department compiles disastrous weather events every year based on the inputs from various State India Meteorological Department (IMD) offices, State Government and Media in the publication "Disaster Weather events". In this paper, we have used this data to analyse various extreme weather events which have affected various regions and the effect of these events on agriculture. The Annual Disastrous Weather Events (DWE) Reports during the period 1967-2016 are used for the analysis. The extreme weather events considered for the analysis are Cold Waves, Heat Waves, Tropical Cyclones, Floods and Lightning.

\footnotetext{
*Corresponding author
}

The number of events recorded every year were tabulated and analysed. The events linked to human causalities have only been considered. The Agriculture data (Kharif Cereal Yields) has been downloaded from 'Directorate of Economics and Statistics' website.

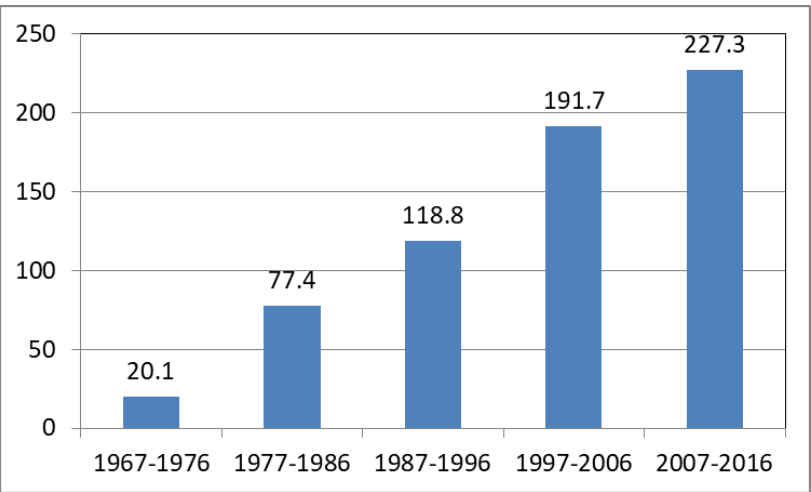

Figure 1. Average Number of extreme events per year by Decade, 1967-2016

\section{WEATHER EXTREMES DURING 1967-2016}

In the past 50 Years, the annual average number of extreme events has been increasing continuously. Figure1 indicates an increasing trend of weather related disasters in various decades. The decadal analysis of the average extreme weather events per year indicates an increase from 20 events per year during the decade 1967-1976 to almost 227 in the last decade (2007-16). The data recorded by the DWE reports indicate an increase of $18 \%$ in the annual extreme weather events in the last decade as compared to the earlier decade (1997-2006) and almost double the events recorded during 1987-1996. The increase in weather related disasters in the past few years were found to be largely due to an increase in the number of floods. A decadal bifurcation of the kind of extreme event indicated heat waves and lightning events contribute most to the increasing trend of 
these disasters. Surprisingly, the average number of floods \& heavy rains per year in the last 3 decades (1987-2016) has remained more or less same but the heat waves have increased by $32 \%$ in this decade as compared to the earlier decade (19972006) \& more than doubled as compared to decade before that (1987-1996). Similarly, the lightning events have also increased by $30 \%$ as compared to the earlier decade and increased 4 times as compared to 1987-1996. The annual average numbers of tropical cyclones and floods have remained unchanged in the last two decades but the cold waves have doubled as compared to earlier decade (Table 1)

\begin{tabular}{|c|r|r|r|r|r|}
\hline Decades & \multicolumn{1}{|c|}{$\begin{array}{c}\text { Cold } \\
\text { waves }\end{array}$} & $\begin{array}{c}\text { Floods \& } \\
\text { heavy } \\
\text { rainfall }\end{array}$ & \multicolumn{1}{|c|}{$\begin{array}{c}\text { Heat } \\
\text { waves }\end{array}$} & \multicolumn{1}{|c|}{$\begin{array}{c}\text { Lightnin } \\
\text { g }\end{array}$} & \multicolumn{1}{c|}{$\begin{array}{c}\text { Cyclone } \\
\text { s }\end{array}$} \\
\hline $1967-1976$ & 1 & 13 & 2 & 0 & 3 \\
\hline $1977-1986$ & 3 & 47 & 6 & 13 & 2 \\
\hline $1987-1996$ & 1 & 70 & 10 & 27 & 3 \\
\hline $1997-2006$ & 2 & 79 & 19 & 81 & 2 \\
\hline $2007-2016$ & 4 & 79 & 25 & 105 & 2 \\
\hline
\end{tabular}

Table.1 Annual Average number of different extreme events

\section{HUMAN LOSS DUE TO WEATHER RELATED DISASTERS}

A comparison of human casualties was done in the last five decades for all extreme weather events except Cyclones (to avoid the bias considering high numbers) and it was found that the numbers in the last decade have decreased as compared to earlier decade but the average number of human deaths in the last two decades is much higher than the earlier decades (Figure 2). Considering data since 1967 , the floods account for $44 \%$ of all the weather related disasters and $52 \%$ of the deaths are due to floods in the present decade. Although the number of average flood events per year have remained around 79 during the last two decades, the causalities have decreased to an annual average of 1371 in present decade as compared to 1700 in the earlier decade and 1460 in the decade before that (1987-1996). In the last 3 decades, the yearly average causalities due to heat waves have increased from 182 to 593 and the lightning causalities have also increased from 70 in the decade 1987-1996 to 427 in the last decade (2007-2016). The average causalities have come down considerably for Cyclones in the last decade and also for cold waves as compared to the earlier decade (Figure 3). In spite of the increase in Cold waves in the last decade, the decrease in the number of casualties indicates a decrease in the severity of the events. The frequency of cyclones has remained unchanged in the past two decades but a considerable decrease in death rate in the last decade (from 1206 in 1997-2006 to 65 in 2007-2016) can be due to accurate early warning, evacuation and better coordination between various disaster managers towards an early action towards mitigation.

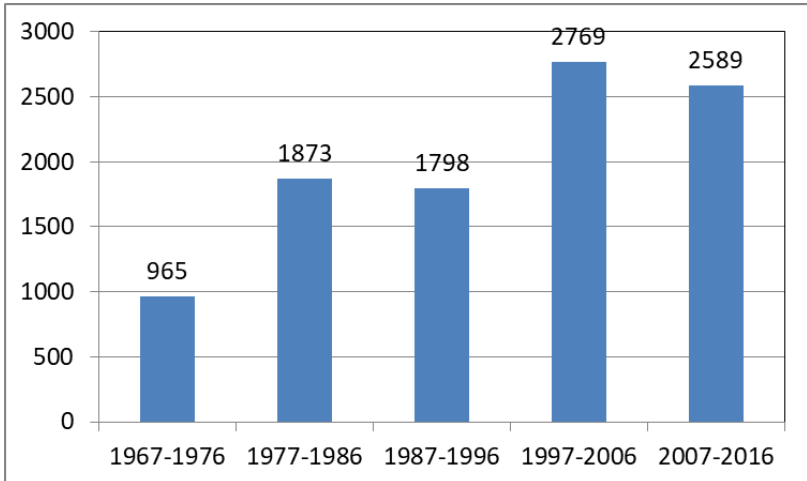

Figure 2. Average number of Deaths per year by Decade 19672016(except due to cyclones)

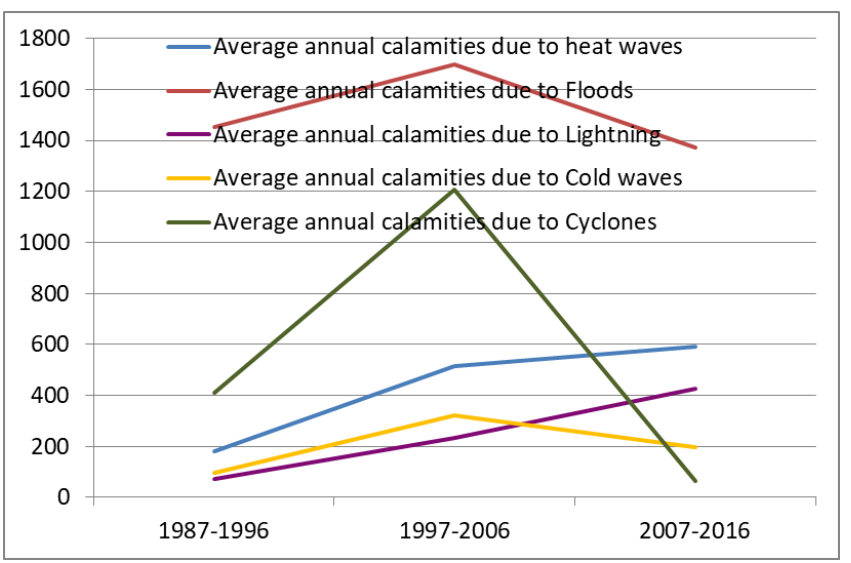

Figure 3. Average annual calamities due to different disasters

\section{IMPACTS ON AGRICULTURE}

Extreme weather events always had an impact on agriculture, particularly thunderstorms (Hails), Cyclones, Floods, Cold Waves and Heat Waves. Several research studies are able to establish the adverse effects of weather extremes especially rainfall and temperature on crop productivity and Yield (Chakraborthy et.al, 2018).

A simple relationship between the all India number of extreme events anomaly per year and the all India food grain anomaly from 1967-2016 indicates an increase from negative to positive anomaly in the past 50 year (Figure 4). Since the impacts of these extreme events include more than $50 \%$ contribution due to increase in floods/heavy rainfall, the positive impact could have been for the rain fed crops. The negative impacts of extreme events are more pronounced at regional scales depending upon the vulnerability of that region, susceptibility of agriculture to a particular extreme weather event and the cropping pattern. 


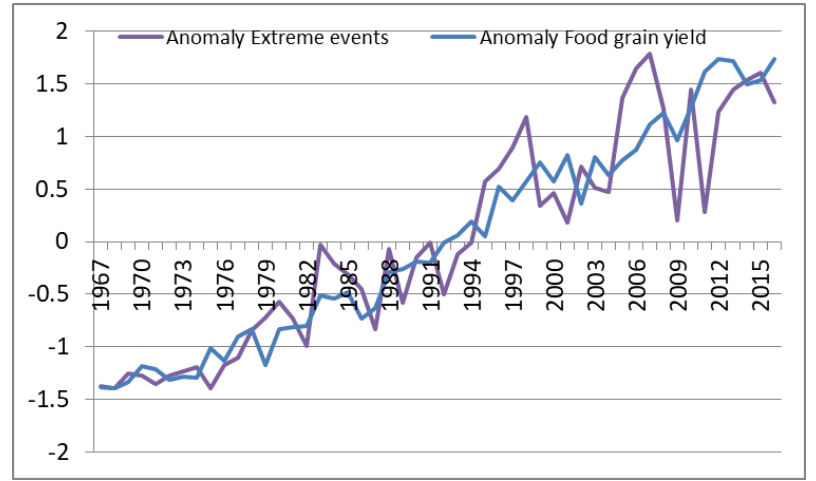

Figure 4. Anomaly of extreme events vis-à-vis anomaly of food grain yield

The top ten states most vulnerable to extreme weather events are listed in Figure 5. Highest number of extreme weather events $(>15 \%)$ have occurred in Maharashtra in the past 50 years followed by West Bengal (9\%), Kerala(7.5\%), Karnataka (7.5\%), Uttar Pradesh (7.1\%), Rajasthan (7.1\%), Odisha (5.2\%) and Bihar (5\%). In Maharashtra, Kerala, and Karnataka more than $90 \%$ of the extreme events are Lightning (Thunderstorms and Hails) and Floods (Heavy rainfall and Flash floods) (Figure 6). In Uttar Pradesh Flood events contribute $45 \%$ followed by cold waves and lightning events contributing remaining $22 \%$ each. In Rajasthan floods and lightning contribute $60 \%$ followed by $40 \%$ due to cold waves and heat waves. In Odisha, frequency of lightning is highest (47\%) followed by floods (25\%), Heat Waves (20\%) and Tropical Cyclones (6.5\%). In Bihar Floods, lightning and Cold Waves are equally frequent $(25-35 \%)$ followed by heat waves. The states most vulnerable to Cyclones are Andhra Pradesh (32\%), Odisha (20\%), West Bengal (15\%), Tamil Nadu (15\%) and Gujarat (5\%).

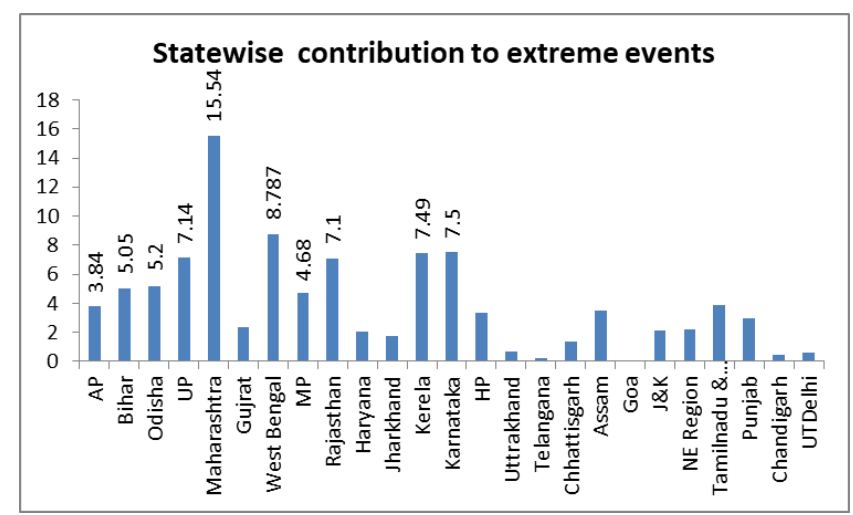

Figure 5. State wise contribution to extreme events

Considering a high percentage of contribution due to floods and heavy rains, the Kharif cereal de-trended anomaly was analysed with respect to the Flood events anomalies. Although on an all India scale the increasing number of extreme events correspond to an increasing Food grain yield but the negative impacts of floods are more pronounced when we analysed the state level yield data. A low negative correlation between the number of flood events and Kharif cereal yield was seen in Maharashtra, Karnataka, and Rajasthan (Figure 7). The time of occurrence of floods was most important in evaluating its influence on crops. The floods during June and July were seen to have contributed to positive yield while flood events during August and
September/October have a negative impact on crop yields. Similarly floods due to Cyclones in May and June do not contribute to negative yield but add moisture and is favourable for sowing of Kharif crops. The floods in October and November damage standing Kharif crop in Coastal states like Odisha, Andhra Pradesh, and West Bengal. Extreme flooding events that occur outside the climatic normal and variability about the mean can cause agriculture damage of varying amounts. It can be direct damage to the standing crops thus affecting crop yield or indirect damage such as long term changes to landscape and soils. The timing of flood is also critical for its impact.

The data analysis at National level does not indicate the full impact of extreme weather events on agriculture. The impacts on agriculture may be more pronounced at a state level or a smaller region depending upon the time of occurrence. The disasters due to extreme weather events although do not show the impact at the national level but they may be causing some percent of loss in national agricultural growth with a much more significant impact at the subnational level. As per FAO report on "The Impact of Disasters on agriculture and food security", the full impact of disasters on agriculture sector due to weather extremes is not well understood but still $25 \%$ of the economic impact caused by climate related disasters falls in the agriculture sector.

The basic requirement for assessment of agrometeorological hazards for extreme events, is an adequate database for assessing the damage in quantitative terms. The meteorological data has to be linked to social, economic and other geographical factors to assess the damage to agriculture. In this paper, we have tried to analyse the frequency of these extreme events and the regions most susceptible to them. Although DWE data utilised in the analysis includes all extreme events with location, severity, and extent of damage qualitatively since 1967 , but the data has become more exhaustive and complete in the last 3 decades only with an increase in disaster awareness, media and, multi organisation networking.

The impacts of extreme events can be positive or negative, they can be direct or indirect and also tangible or intangible (Handmer \& Smith, 1992).We in our analysis have addressed only the direct impacts i.e. the effect of frequency of these events on crop yields and also some intangible impacts, through the use of social indicators such as the number of human deaths. A significant part of agriculture production losses is caused due to floods due to heavy rains or cyclones. The inundation due to floods associated with cyclones may cause salinization of soils but at the same time they may also recharge the soil moisture and provide extra storage in rivers, lakes, ponds and small reservoirs, which may improve the water supply in the area for irrigated agriculture, making crops less susceptible to dry spells. (Ryan, 1993).Although positive impacts can be shown to occur for some extreme events, but it is the negative or adverse impacts, which are more pronounced and affect human society significantly (Joy, 1991).

\section{REFERENCES}

Azhar GS, Mavalankar D, Nori-Sarma A, Rajiva A, Dutta P, Jaiswal A, Sheffield P, Knowlton K, Hess JJ, 2014. Heatrelated mortality in India: excess all-cause mortality associated with the 2010 Ahmedabad heat wave. PLoS ONE, 9(3):e91831 
Chakraborty, D., Sehgal, V.K., Dhakar, R., 2018. Changes in daily maximum temperature extremes across India over 19512014 and their relation with cereal crop productivity. Stochastic Environmental Research \& Risk Assessment, https://doi.org/10.1007/s00477-018-1604.

Chattopadhyay,N., Sunitha,S., John,G., Choudhari,V.R., 2017. Occurence of hail storms and Strategies to minimize its effect on crops. MAUSAM,68(1):75-92

Dash SK, Mamgain A, 2011. Changes in the frequency of different categories of temperature extremes in India. J Appl Meteorol Climatol,50(9):1842-1858

H.P.Das,T.I.,Adamenko,K.A.Anaman, R.G.Gommes \& G.Johnson, 'Agrometeorology related to extreme events', WMO Technical Note No.201 (CAgM-XI Working Group on Agrometeorolgy related to extreme events)
Handmer,J and Smith, D.J., 1992Cost-effectiveness of flood warnings. Report prepared for the Australian Bureau of Meteorology by the Centre for resources \&environmental studies, Ausytalian national University, Canberra, Australia, pp50.

Joy, C.S., 1991. The cost of natural disasters in Australia, Paper presented at the climate change: Impacts \& adaptation workshop, Climate Impacts Centre, Macquarie University ,Sydney, Australia.

Ryan,C.J., 1993. Costs and benefits of tropical cyclones, severe thunderstorms \& bush fires in Australia. Climatic Changes, 25:353-367

Sugg, A.L., 1968. Beneficial aspects of tropical cyclone, J.Appl.Meteorology,(1),39-43

WMO Report, 1997. Extreme agrometeorological events CAgM, Report No.73,TD No.836,WMO, Geneva.

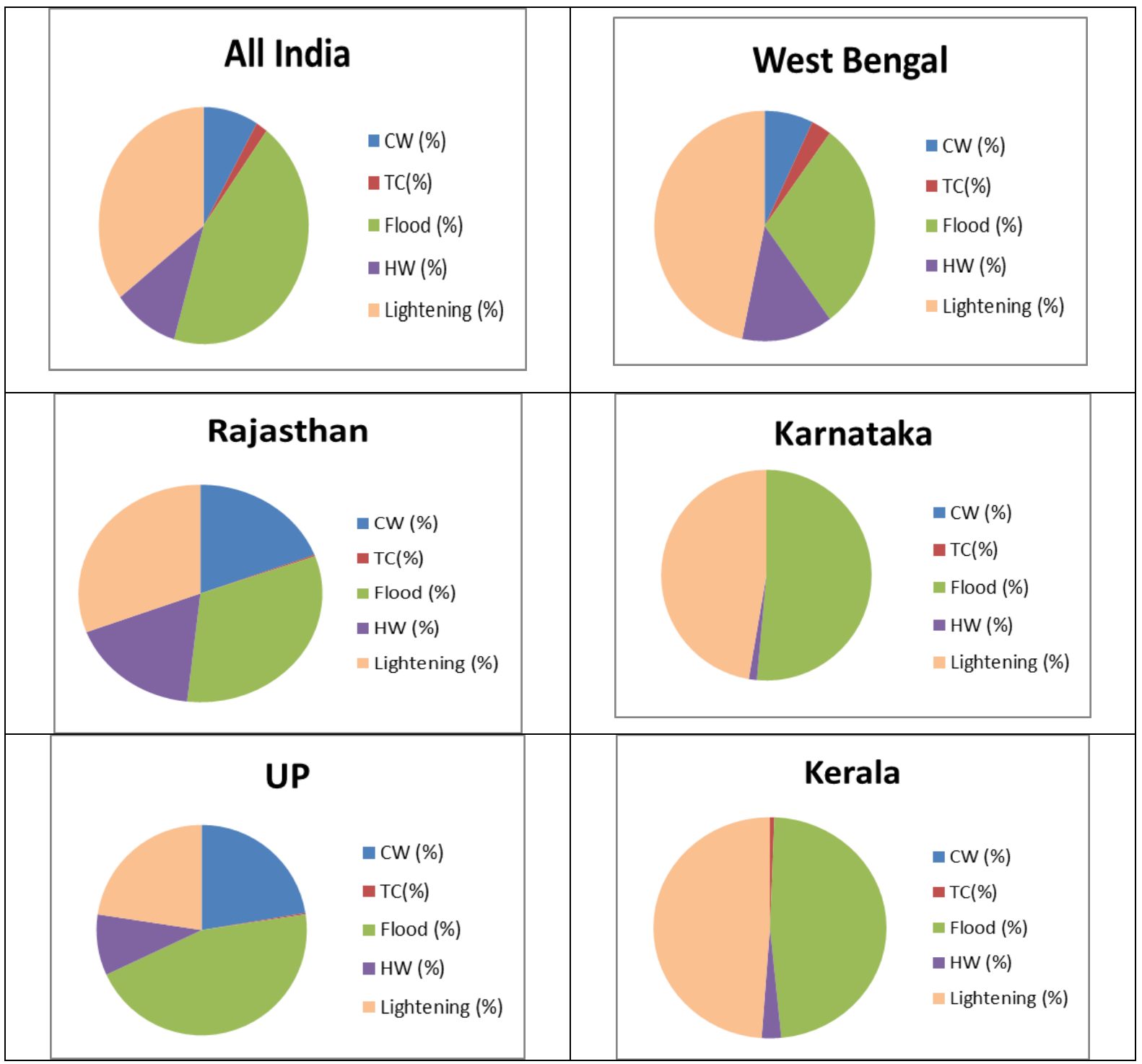

Figure 6 Percentage Frequency of various extreme weather events (Cold Wave CW: Tropical Cyclone TC: Heat Wave HW) 


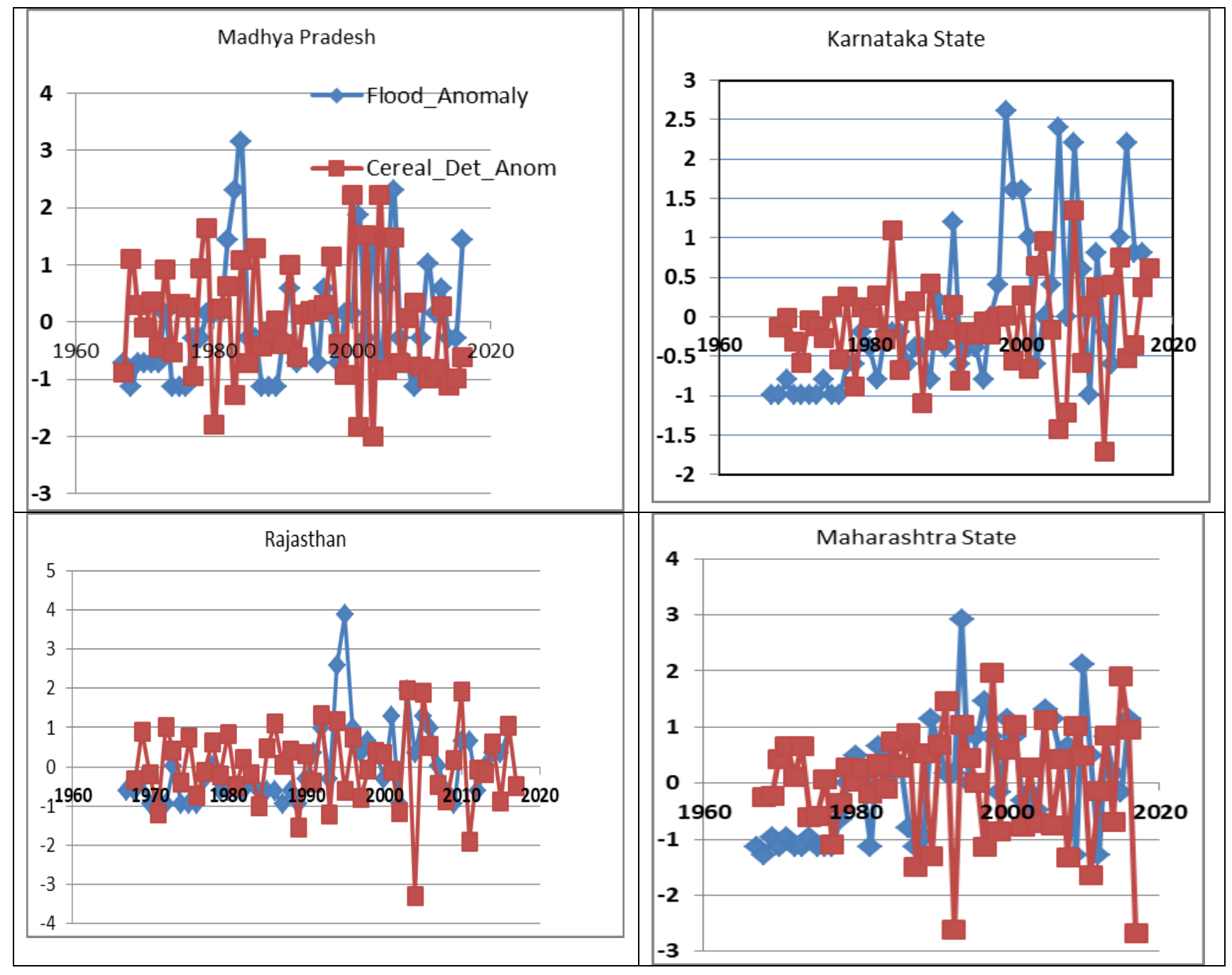

Figure 7 Flood anomaly Vs Total Kharif Cereal Detrended Yield for various States having highest number of Flood events. 